MEIRELLES-BARTOLI, R.B., SOUSA, D.B. e MATHIAS, L.A. Aspectos da brucelose na saúde pública veterinária. PUBVET, Londrina, V. 8, N. 10, Ed. 259, Art. 1722, Maio, 2014.

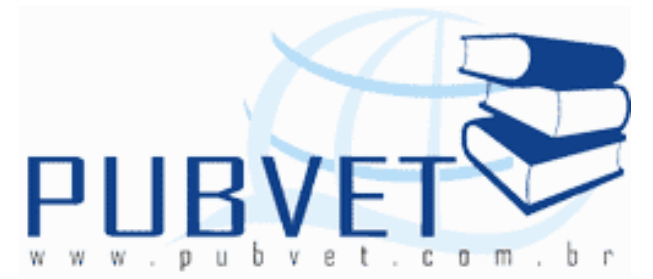

PUBVET, Publicações em Medicina Veterinária e Zootecnia.

\title{
Aspectos da brucelose na saúde pública veterinária
}

\author{
Raphaella Barbosa Meirelles-Bartoli ${ }^{1}$, Daniel Bartoli de Sousa ${ }^{1}$, \\ Luis Antonio Mathias ${ }^{2}$
}

${ }^{1}$ Docentes do Curso de Medicina Veterinária da Universidade Federal de Goiás (UFG), Campus Jataí, Unidade Jatobá, Laboratório de Sanidade Animal.

${ }^{2}$ Docente do Curso de Medicina Veterinária da Universidade Estadual Paulista, Faculdade de Ciências Agrárias e Veterinárias, Departamento de Medicina Veterinária Preventiva e Reprodução Animal.

\section{Resumo}

A brucelose é uma doença infectocontagiosa, de evolução crônica e de caráter granulomatoso típico, que acomete principalmente o sistema reprodutivo e o osteoarticular de animais domésticos, silvestres e de seres humanos. É uma antropozoonose caracterizada pela infecção das células do sistema mononuclear fagocitário, provocada por uma bactéria pertencente ao gênero Brucella. Com ampla distribuição mundial, tem em nosso país uma alta incidência e prevalência no rebanho bovino, servindo como principal fonte de infecção para os seres humanos. Mesmo sendo uma enfermidade de caráter ocupacional acometendo trabalhadores que estão em contato direto com animais doentes, também possui caráter populacional, pois a ingestão de produtos de origem animal contaminados torna-se importante meio de transmissão desta bactéria. Embora seja caracterizada por uma grave 
MEIRELLES-BARTOLI, R.B., SOUSA, D.B. e MATHIAS, L.A. Aspectos da brucelose na saúde pública veterinária. PUBVET, Londrina, V. 8, N. 10, Ed. 259, Art. 1722, Maio, 2014.

zoonose, esta doença ainda é pouco conhecida por várias pessoas devido às inúmeras subnotificações.

Palavras-chave: controle, epidemiologia, zoonoses.

\title{
Aspects of the brucellosis in the veterinary public health
}

\begin{abstract}
The brucellosis is an infectious disease of chronic evolution and character typical granulomatous disease mainly affecting the reproductive system and the musculoskeletal domestic animals, wildlife and humans. It's a anthropozoonosis characterized by infection of the cells of the mononuclear phagocyte system, caused by bacteria of the genus Brucella. With worldwide distribution, in our country has a high incidence and prevalence in cattle, serving as the main source of infection for humans. Although a character occupational illness affecting workers who are in direct contact with sick animals, also features character population, because the intake of animal products contanimados become important means of transmission of this bacterium. Although it is characterized by a serious zoonotic disease, this disease is still poorly understood by many people because of the many understatements.
\end{abstract}

Keywords: control, epidemiology, zoonosis.

\section{INTRODUÇÃO}

A brucelose possui ampla distribuição mundial, sendo endêmica no Brasil. Doença que provoca graves perdas na produção animal, chegando a causar $25 \%$ de diminuição na produção de leite e $15 \%$ na de carne, sem contar com a perda de bezerros ocasionada por abortamentos. Além disso, a sua presença torna o país vulnerável a barreiras sanitárias internacionais. É uma antropozoonose de evolução preferencialmente crônica e caráter granulomatoso difuso, caracterizada pela infecção das células do sistema 
MEIRELLES-BARTOLI, R.B., SOUSA, D.B. e MATHIAS, L.A. Aspectos da brucelose na saúde pública veterinária. PUBVET, Londrina, V. 8, N. 10, Ed. 259, Art. 1722, Maio, 2014.

mononuclear fagocitário, provocada por uma bactéria intracelular facultativa pertencente ao gênero Brucella (PAULIN \& FERREIRA, 2003).

A Brucella é um cocobacilo Gram-negativo que mede de 0,4 a $0,8 \mu \mathrm{m}$ de diâmetro por 0,6 a 3,0 $\mu \mathrm{m}$ de comprimento (DEYOE, 1992). O organismo não tem motilidade e não forma esporos (ALTON, 1990).

As brucelas, quando cultivadas em meios sólidos, apresentam duas possíveis morfologias de colônias, lisas ou rugosas, decorrentes da constituição química da parede celular. Além de determinar a morfologia colonial, a composição química das paredes celulares das brucelas é elemento central nos fenômenos imunológicos. As espécies lisas possuem uma membrana citoplasmática interna, um espaço periplasmático contendo uma camada de peptideoglicano e uma parede externa. $\mathrm{Na}$ parede externa existe uma estrutura formada por moléculas de constituição lipopolissacarídica, o LPS, composto pelos lipídios A, um oligossacarídeo central e uma cadeia polissacarídica mais exposta denominada cadeia $\mathrm{O}$. A estrutura das brucelas rugosas é parecida com a das lisas, porém nas rugosas a cadeia O está totalmente ausente ou presente de forma residual (CORBEL, 1997).

O gênero é composto por nove espécies (FOSTER et al., 2007; SCHOLZ et al., 2008). B.melitensis, B.suis e B.abortus são espécies lisas. A B.abortus subdivide-se em sete biovares $(1,2,3,4,5,6,9)$, a $B$.melitensis em três $(1,2$ e 3) e a B.suis em cinco (1, 2, 3, 4 e 5). As rugosas, embora apresentem variantes, não se subdividem em biovares (PAULIN \& FERREIRA, 2003). As duas únicas espécies naturalmente rugosas são B.canis e B.ovis (CORBEL, 1997). As espécies B.neotomae e B.microti, isoladas de roedores silvestres, não são consideradas zoonóticas (CORBEL, 1997; SCHOLZ et al., 2008), assim como a B.ovis, que foi isolada apenas de ovinos naturalmente infectados (CORBEL, 1997). A B.ceti e B.pinnipedialis, patogênicas para mamíferos marinhos (FOSTER et al., 2007), já foram associadas a granulomas intracerebrais em pacientes com neurobrucelose (SOHN et al., 2003), osteomielite da coluna vertebral (MCDONALD et al., 2006) e a acidentes laboratoriais (BREW et al., 1999). 
MEIRELLES-BARTOLI, R.B., SOUSA, D.B. e MATHIAS, L.A. Aspectos da brucelose na saúde pública veterinária. PUBVET, Londrina, V. 8, N. 10, Ed. 259, Art. 1722, Maio, 2014.

No Estado de Oregon, nos EUA, DE et al. (2008), relataram as características microbiológicas, bioquímicas e moleculares de uma linhagem de Brucella incomum (BO1) isolada de uma prótese de seio (silicone) de uma senhora com 71 anos de idade com sinais clínicos compatíveis. A análise inicial, incluindo teste de susceptibilidade bioquímica, análise de ácidos graxos e análise molecular baseada na reassociação do DNA-DNA e na presença de múltiplas cópias do IS 711, sugeriu que o isolado era uma Brucella like organism, mas a determinação de espécie, por meio de dados moleculares baseados no sequenciamento do $16 \mathrm{~S}$ rARN e na análise sequencial multilócus, demonstrou que a BO1 era uma cepa incomum, atípica e nova de Brucella, denominada, por SCHOLZ et al. (2010), Brucella inopinata.

Recentemente uma nova espécie de brucela foi isolada, mas ainda não possui classificação nem está na lista oficial descrita pelo Subcomitê de Taxonomia da Brucella (INTERNATIONAL COMMITTEE ON BACTERIAL TAXONOMY. SUBCOMMITTEE ON TAXONOMY OF BRUCELLA, 2010). No Texas (EUA), SCHLABRITZ-LOUTSEVITCH et al. (2009) descreveram e relataram pela primeira vez um novo isolado de Brucella associado a dois casos de morte neonatal em primatas (babuínos). As amostras do útero isoladas foram caracterizadas utilizando os testes bioquímicos tradicionais, PCR e sequenciamento de multilócus. Os isolados, morfologicamente, se assemelham a Brucella, embora suas características não sejam consistentes com qualquer espécie descrita.

Dentro do gênero Brucella, cada espécie possui hospedeiro preferencial: B.abortus, bovinos e bubalinos; B.melitensis, caprinos e ovinos; B.suis, suínos; B.ovis, ovinos; B.canis, canídeos (NICOLETTI, 1992); B.neotomae e B.microti, roedores silvestres (CORBEL, 1997; SCHOLZ et al., 2008); e as espécies B.ceti e B.pinnipedialis, mamíferos marinhos (FOSTER et al., 2007).

A espécie mais patogênica e invasora para o homem é a B.melitensis, seguida de B.suis, B.abortus e B.canis, embora a penúltima seja a mais frequente causadora de infecções humanas no mundo (ACHA \& SZYFRES, 
MEIRELLES-BARTOLI, R.B., SOUSA, D.B. e MATHIAS, L.A. Aspectos da brucelose na saúde pública veterinária. PUBVET, Londrina, V. 8, N. 10, Ed. 259, Art. 1722, Maio, 2014.

2001). Até o presente momento, a B.melitensis não foi isolada no Brasil, sendo considerada exótica em nosso país (POESTER et al., 2002).

\section{EPIDEMIOLOGIA}

\section{Distibuição}

É uma doença que ocorre em vários países do mundo, a distribuição das diferentes espécies de Brucella e seus biovares apresenta variações geográficas. A B.abortus é a mais amplamente difundida. A B.melitensis e B.suis têm uma distribuição irregular. A infecção por B.canis foi comprovado em muitos países de vários continentes, e pode-se afirmar que sua distribuição é universal. A B.ovis parece estar distribuída em todos os países onde a cria de ovinos é importante (ACHA \& SZYFRES, 2001).

\section{Mecanismos de Transmissão}

Embora no gênero Brucella, suas espécies podem ter predileção por determinada espécie animal as diferentes brucelas podem acometer diversas outras espécies. Os gatos, porém, são resistentes a brucela. (BATHKE, 1999).

A principal fonte de infecção é representada pela fêmea prenha, que elimina grandes quantidades do agente por ocasião do aborto ou parto e em todo o período puerperal (até, mais ou menos, 30 dias após o parto), contaminando pastagens, água, alimentos e fômites. Entretando qualquer hospedeiro vertebrado doente ou portador sadio que albergue as brucelas e as elimine no ambiente são importantes fontes de infecção. Essas bactérias podem permanecer viáveis no meio ambiente por longos períodos, dependendo das condições de umidade, temperatura e sombreamento, ampliando de forma significativa a chance de o agente entrar em contato e infectar um novo indivíduo suscetível (LUSHSINGER et al., 1965).

No animal infectado, as localizações de maior frequência do agente são os linfonodos, como também no baço, fígado, aparelho reprodutor masculino, útero e úbere. As vias de eliminação são representadas principalmente pelos 
MEIRELLES-BARTOLI, R.B., SOUSA, D.B. e MATHIAS, L.A. Aspectos da brucelose na saúde pública veterinária. PUBVET, Londrina, V. 8, N. 10, Ed. 259, Art. 1722, Maio, 2014.

fluidos e anexos fetais, eliminados no parto ou no abortamento e durante todo o puerpério, além do leite e do sêmen. A mais importante porta de entrada é o trato digestivo, sendo que a infecção se inicia quando um animal suscetível ingere água e alimentos contaminados ou pelo hábito de lamber as crias recém-nascidas. Um animal pode adquirir a doença apenas por cheirar fetos abortados, pois a bactéria também pode entrar pelas mucosas do nariz e dos olhos (EAGLESOME \& GARCIA, 1997).

A transmissão pelo coito parece não ser de grande importância entre bovinos e bubalinos. Na monta natural, o sêmen é depositado na vagina onde há defesas inespecíficas que dificultam o processo de infecção. Entretanto, um touro infectado não pode ser utilizado como doador de sêmen; isso porque, na inseminação artificial, o sêmen é introduzido diretamente no útero, permitindo infecção da fêmea com pequenas quantidades do agente, sendo por isso importante via de transmissão e eficiente forma de difusão da enfermidade nos plantéis. A transferência de embriões, realizada segundo os protocolos internacionalmente preconizados de lavagem e tratamento para a redução da transmissão de agentes infecciosos, não apresenta risco de transmissão de brucelose entre doadoras infectadas e receptoras livres da doença (BRASIL, 2001). Já a brucelose suína é considerada uma doença sexualmente transmissível. Fêmeas podem facilmente infectar-se através de varrões infectados ou sêmen contaminado. Os suínos estão suscetíveis à brucelose a partir dos quatro a cinco meses de idade, aproximação da puberdade (SOBESTIANSKY et al., 1994).

A principal forma de entrada da brucelose em uma propriedade é a introdução de animais infectados. Quanto maior a frequência de introdução de animais, maior o risco de entrada da doença no rebanho. Por essa razão, devese evitar introduzir animais cuja condição sanitária é desconhecida. O ideal é que esses animais procedam de rebanhos livres ou, então, que sejam submetidos à rotina diagnóstica que lhes garanta a condição de não infectados (BRASIL, 2001). 
MEIRELLES-BARTOLI, R.B., SOUSA, D.B. e MATHIAS, L.A. Aspectos da brucelose na saúde pública veterinária. PUBVET, Londrina, V. 8, N. 10, Ed. 259, Art. 1722, Maio, 2014.

Os hospedeiros susceptíveis são os bovinos, equinos, ovinos, caprinos, suínos e caninos, e o homem. Animais jovens são refratários à doença até atingirem a maturidade sexual, podendo ser portadores e vir a desenvolver brucelose posteriormente. As bezerras que se mantêm afastadas das vacas possuem uma frequência de infecção mais baixa. Os novilhos e os machos castrados possuem pouca importância na epidemiologia da doença (ACHA \& SZYFRES, 2001).

\section{PATOGENIA}

Uma vez atravessando a porta de entrada, as brucelas serão drenadas para os gânglios linfáticos regionais e a partir destes, via linfa ou sangue, disseminam-se por todo o organismo, colonizando os órgãos ou tecidos ricos em células do sistema mononuclear fagocitário, tais como gânglios linfáticos, medula óssea, fígado, baço e articulações (BATHKE, 1999). Além destes, as brucelas se disseminam para órgãos reprodutivos como útero gravídico das fêmeas e os testículos, epidídimo e vesícula seminal dos machos. A predileção pelo útero gravídico se deve a sua produção do hormônio chamado eritritol. $\mathrm{O}$ eritritol atrai as brucelas e funciona como fator estimulante para o seu crescimento. Este hormônio só está presente em bovinos, caprinos, ovinos, suínos e caninos, e está relacionado com a ocorrência do abortamento. Este hormônio não é produzido pela mulher ou pela égua (CORRÊA \& CORRÊA, 1992), entretanto a possibilidade das brucelas causarem abortamento em mulheres não é afastada. Nos homens pode ocorrer orquite e epididimite (PAULIN \& FERREIRA, 2003).

\section{ASPECTOS EPDEMIOLÓGICOS DA BRUCELOSE COMO ZOONOSE}

A brucelose é uma antropozoonose conhecida desde épocas remotas, há registros de que Hipócrates, em 460 a.C., fazia referência a pacientes com sintomas compatíveis com esta enfermidade. Pesquisas recentes, realizadas na 
MEIRELLES-BARTOLI, R.B., SOUSA, D.B. e MATHIAS, L.A. Aspectos da brucelose na saúde pública veterinária. PUBVET, Londrina, V. 8, N. 10, Ed. 259, Art. 1722, Maio, 2014.

Itália, revelaram que esqueletos remanescentes de pessoas que sucumbiram à catástrofe do vulcão Vesúvio, na cidade de Herculano, ocorrida no ano 79 da era cristã, apresentavam lesões ósseas típicas de brucelose. Uma provável explicação para esse fato foi proporcionada pela microscopia eletrônica, que revelou a presença de cocobacilos compatíveis com Brucella em queijos elaborados com leite de cabras e que foram encontrados carbonizados em escavações naquela cidade italiana (CAPASSO, 2002).

No Estado de São Paulo, nos anos de 1977 a 1987, Feitosa e colaboradores realizaram um levantamento sorológico da brucelose em sete espécies animais, inclusive a humana, em sete regiões do estado de São Paulo. Foi examinado um total de 72.338 amostras de soro, sendo 50.692 bovinos, 8.123 bubalinos, 78 caninos, 235 caprinos, 348 equinos, 12.706 suínos e 156 humanos, e realizadas 89.160 provas sorológicas, sendo 48.906 soro aglutinação rápida (SAR), 6.461 soro aglutinação lenta (SAL), 32.159 "card test" (CT) e 1.634 provas do mercaptoetanol (ME). Os resultados evidenciaram maior incidência de positivos nas espécies: humana $(71,43 \%)$ e bovina $(63,64 \%)$, ambas pela prova $M E$, seguindo-se a bubalina $(28,88 \%)$ e canina (9,09\%), pela prova do CT, equina $(16,67 \%)$ e suína $(13,23 \%)$, na SAL e caprina $(0,58 \%)$ na SAR (FEITOSA et al., 1991).

As ocorrências da infecção humana estão vinculadas à prevalência da infecção nos reservatórios animais. As infecções por B.abortus e B.suis costumam afetar principalmente grupos ocupacionais, enquanto que as causadas por B.melitensis ocorrem com mais frequência que as anteriores na população em geral. A prevalência mais alta no homem encontra-se nos países com taxas elevadas de brucelose por B.melitensis, em caprinos ou ovinos ou em ambas as espécies (ACHA \& SZYFRES, 2001).

\section{Infecção por meio de alimentos contaminados}

Os queijos frescos e o leite cru de cabra ou ovelha contaminados por B.melitensis são os veículos mais frequentes da infecção e podem originar múltiplos casos de brucelose humana. Também se conhecem surtos 
MEIRELLES-BARTOLI, R.B., SOUSA, D.B. e MATHIAS, L.A. Aspectos da brucelose na saúde pública veterinária. PUBVET, Londrina, V. 8, N. 10, Ed. 259, Art. 1722, Maio, 2014.

epidêmicos originados de vacas infectadas por B.suis. O leite de vacas e os produtos lácteos que contém B.abortus podem dar origem a casos esporádicos (ACHA \& SZYFRES, 2001).

Devido à situação que a brucelose representa à saúde pública, começouse a desenvolver diversas pesquisas no mundo todo, inclusive no Brasil e foi em 1977 que Souza e colaboradores, na região de Ribeirão Preto, no Estado de São Paulo, a partir da deteç̧ão de um rebanho leiteiro brucélico investigaram os consumidores humanos do leite suspeito. Foram feitas provas sorológicas para diagnóstico de brucelose no rebanho leiteiro e na população humana consumidora do leite. Observou-se que cerca de $8 \%$ das vacas em lactação na época do levantamento foram consideradas brucélicas. Entre os consumidores não se observaram casos de sorologia positiva para brucelose. Concluiu-se que apesar da importância da brucelose como zoonose, ela continua endêmica no nosso meio criatório. A fervura do leite é uma medida eficaz e deve ser preconizada nas regiões onde o leite é consumido "in natura", como medida de escolha em saúde pública (SOUZA et al., 1977).

Com o objetivo de recuperar B.abortus do leite, Botelho et al (2000) utilizaram 14 amostras de leite "in natura" de fêmeas bovinas soropositivas para brucelose procedentes de sete propriedades rurais situadas nos municípios de Pedra e Ventura, no Estado de Pernambuco. As amostras de leite foram centrifugadas e os sedimentos obtidos foram tratados com antibióticos e antifúngicos e inoculados em cobaias, por via intraperitoneal. Das vinte e oito cobaias inoculadas, cinco $(17,85 \%)$ apresentam reação sorológica positiva nos testes de soroaglutinação rápida (SAR), soroaglutinação lenta (SAL) e 2-Mercaptoetanol (2-ME), demonstrando uma possível infecção destes animais pela B.abortus presente no leite. Na pesquisa de aglutininas anti-Brucella abortus em soros de humanos observou-se que oito amostras $(21,05 \%)$ apresentavam pelo menos uma das provas positiva, sugerindo possível infecção dos humanos pelo consumo do leite e subprodutos "in natura". 
MEIRELLES-BARTOLI, R.B., SOUSA, D.B. e MATHIAS, L.A. Aspectos da brucelose na saúde pública veterinária. PUBVET, Londrina, V. 8, N. 10, Ed. 259, Art. 1722, Maio, 2014.

Langoni et al. (2000) considerando o pequeno número de dados brasileiros sobre presença de brucela em leite cru e derivados nãopasteurizados, estudaram a presença deste agente em leite de animais sorologicamente positivos. Amostras diárias de $300 \mathrm{~mL}$ de leite foram colhidas por três dias de todos os quartos mamários produtivos ( $75 \mathrm{~mL} /$ teto). Das 49 amostras examinadas, isolou-se Brucella abortus de quinze, correspondendo a $30,61 \%$ do total.

Marques et al (2000) apresentaram o estudo retrospectivo de 64 crianças com brucelose, de idades compreendidas entre 13 meses e 14 anos, diagnosticada no Hospital Distrital de Bragança Paulista, no estado de São Paulo, entre $1^{0}$ de janeiro de 1995 e 31 de dezembro de 1998. Foram estudados os parâmetros epidemiológicos, laboratoriais e terapêuticos. O meio de transmissão provável foi identificado na totalidade das crianças, sendo na sua maior parte por ingestão de leite não-pasteurizado e/ou contacto com animais. Os autores encontraram um predomínio significativo no sexo masculino $(67,2 \%)$. Os principais sinais e sintomas apresentados foram a artralgia/artrite, febre, anorexia e astenia. Ocorreram recidivas em três crianças e reinfecções em quatro casos.

Na América Latina, os países que registram maior número de casos foram Argentina, México e Peru. Em outros continentes, o mesmo se sucede nos países que margeiam o Mar Mediterrâneo, e no Iran, no sudeste da Rússia, a na Mongólia (ACHA \& SZYFRES, 2001).

Na Arábia Saudita, foram relatados onze casos de crianças infectadas por B.melitensis devido à ingestão de leite não pasteurizado de cabras. Estas apresentavam febre intermitente e foram tratadas com sucesso com uma combinação de rifampicina e estreptomicina (FACHARZT \& HARLAND,1986).

Israel é um dos países do mediterrâneo que a brucelose é endêmica. Também há ocorrido surtos em "kibbutz" devido o trabalho com animais e o consumo de leite não pasteurizado (MISHAL et al., 1999).

Um estudo feito nos estados da Austrália, entre os anos de 1967 a 1971, demonstrou o número de casos que ocorreram neste país devido a diversos 
MEIRELLES-BARTOLI, R.B., SOUSA, D.B. e MATHIAS, L.A. Aspectos da brucelose na saúde pública veterinária. PUBVET, Londrina, V. 8, N. 10, Ed. 259, Art. 1722, Maio, 2014.

fatores. Em 1971, a distribuição entre os estados foram 40 casos em Victoria, 21 em New South Wales, 11 em Queensland, 4 em South Austrália e 1 em Western Australian. Analisados os casos de Victoria, em particular, pode-se observar que a principal via de transmissão da enfermidade foi por consumo de leite. Dos 36 pacientes, 12 se infectaram por leite contaminado. Dos demais pacientes, dez foram trabalhadores de frigoríficos, cinco trabalhavam em propriedades infectadas, dois foram por infecção acidental e os outros sete não se sabe a causa (ALTON \& GULASEKHARAM, 1974).

Onze casos de brucelose foram identificados entre os meses de janeiro a março de 2002, na Espanha, no município de Córdoba, em Andalucia. As pessoas infectadas consumiram queijos de leite de cabra não pasteurizado. Foi feita uma pesquisa com amostras de tecido e leite dos animais do rebanho, encontrando B.melitensis biovar 3 (MÉNDEZ et al., 2003).

Embora medidas de saúde pública agressivas terem sido adotadas nos EUA e gerado uma enorme redução no número de casos de brucelose humana, este país tem tido sérios problemas com a incidência de casos na Califórnia, Texas e outros estados que fazem fronteiras com o México. Foram relatados 28 pacientes diagnosticados com a enfermidade no Hospital da Universidade de San Diego, Califórnia entre os anos de 1979 e 2002, e foi observada uma nova tendência epidemiológica. Até os anos de 1992, o agente causador da infecção na grande maioria foi a B.abortus (73\%). Depois deste ano, a B.melitensis passou a ser a principal responsável, sendo que mulheres foram mais comumente infectadas do que os homens ( $77 \%$ e $39 \%$, respectivamente). 0 principal fator de risco são as viagens para o México com a ingestão de produtos lácteos não pasteurizados (TROY et al., 2005).

Nas regiões árticas e subárticas foram comprovados casos de humanos infectados por brucelose devido ao hábito de ingerir medula óssea ou carnes cruas de renas que estavam infectadas com B.suis biótipo 4 (ACHA \& SZYFRES, 2001). 
MEIRELLES-BARTOLI, R.B., SOUSA, D.B. e MATHIAS, L.A. Aspectos da brucelose na saúde pública veterinária. PUBVET, Londrina, V. 8, N. 10, Ed. 259, Art. 1722, Maio, 2014.

Também é possível que as verduras cruas e a água contaminada com excretas de animais infectados sirvam de via de transmissão (ACHA \& SZYFRES, 2001).

\section{Enfermidade ocupacional}

Nas áreas enzoóticas de brucelose bovina e suína, predomina o modo de transmissão por contato. A brucelose humana é, em grande parte, uma enfermidade ocupacional de trabalhadores pecuários, ordenhadores, magarefes e trabalhadores de frigorífico em geral, açougueiros, trabalhadores na industria de laticínios e Médicos Veterinários. A infecção é contraída geralmente ao manipular fetos e envoltórios fetais ou ao entrar em contato com secreções vaginais e excrementos de animais infectados (ACHA \& SZYFRES, 2001).

Nas regiões onde existe B.melitensis, o número de enfermos é muito elevado. A primeira comprovação bacteriológica na República Argentina ocorreu em 1930. Neste país, a brucelose é considerada uma enfermidade profissional desde 1932, quando foi incluída na regulamentação da lei de acidentes de trabalho. Entre 1945 e 1976 foram examinados 714 enfermos de áreas rurais e de matadouros e isolaram 157 cepas de B.abortus, 30 de B.suis e 22 de B.melitensis. Entre os anos de 1965 e 1983, também na Argentina, de 148 cepas de Brucella isoladas do homem, 47 foram B.suis biótipo 1, e 32 foram de B.suis "atípica" o que contrasta com os $95 \%$ de B.melitensis encontrado anteriormente e com os $75 \%$ de B.abortus descrito por outros autores. Os $50 \%$ das cepas tipificadas procedem de trabalhadores de matadouros. A B.abortus biotipo 4 foi isolada de um paciente de brucelose crônica. Destaca-se a ausência na América Latina de isolamentos anteriores deste biótipo no homem, apesar de ser encontrado com muita frequência nos animais (GARCÍA-CARRILLO et al., 1985)

Em julho de 1971, no município de Salvador, na Bahia, estudou-se a brucelose humana do ponto de vista sorológico, ocupacional e clínico, em 128 operários de um frigorífico, distribuídos em 8 seções de trabalho. Através de um método em que o médico aplicava um questionário individual pré- 
MEIRELLES-BARTOLI, R.B., SOUSA, D.B. e MATHIAS, L.A. Aspectos da brucelose na saúde pública veterinária. PUBVET, Londrina, V. 8, N. 10, Ed. 259, Art. 1722, Maio, 2014.

codificado para a obtenção de dados históricos e em seguida um técnico de laboratório colhia o sangue dos funcionários para realização da sorologia procedida pelo Médico Veterinário em laboratório independente. Encontrou-se uma frequência de $10,58 \%$ de indivíduos com sorologia positiva. Quanto ao aspecto ocupacional, ficou bem caracterizada a importância do tempo de trabalho no frigorífico. Dos positivos, 55,55\% tinham mais de cinco anos na ocupação atual, bem como a seção de trabalho destacou-se neste mesmo sentido; $33,33 \%$ e $30,00 \%$ dos positivos trabalham nas seções de suínos e triparia, respectivamente (SPÍNOLA \& COSTA, 1972).

Um inquérito realizado em populações rurais de 15 municípios da Zona Sul do Rio Grande do Sul, entre julho de 1970 a outubro de 1975, demonstrou que o índice de prevalência da brucelose humana nesta região é reduzido, e que a infecção por interessar mais as pessoas do sexo masculino, configura característica de doença ocupacional, isso por que no exame de 4.983 amostras de sangue submetidos à reação de fixação do complemento em placa com antígeno aquoso de B.abortus, 25 reagiram positivamente para brucelose $(0,50 \%)$. Das 25 positivas, 17 pertencem ao sexo masculino (1,04\%) e 8 ao feminino $(0,45 \%)$. Foram encontrados reatores para brucelose só em 9 dos 15 municípios considerados, totalizando 3.395 amostras, com índice de prevalência de 0,73\% (BARUFFA, 1978).

Pela primeira vez foi realizado um levantamento em São Luís do Maranhão, em 1995, com a finalidade de identificar a prevalência da brucelose em trabalhadores de matadouro. A programação experimental constou de inquérito epidemiológico prévio e pesquisa de aglutininas anti-Brucella sp, através de provas de soro-aglutinação e fixação de complemento efetuadas em 230 amostras de soro sanguíneo colhidas de trabalhadores do matadouro industrial de São Luís. Os resultados de ambas as provas foram coincidentes e evidenciaram o coeficiente de prevalência de 2,17\%, comprovando a presença da enfermidade em grupos ocupacionais (COELHO et al., 1995).

Com o objetivo de identificar e quantificar o risco de infecção por B.abortus nas diferentes tarefas em abatedouros frigoríficos, coletaram sangue 
MEIRELLES-BARTOLI, R.B., SOUSA, D.B. e MATHIAS, L.A. Aspectos da brucelose na saúde pública veterinária. PUBVET, Londrina, V. 8, N. 10, Ed. 259, Art. 1722, Maio, 2014.

de 127 funcionários de seis abatedouros com inspeção estadual, do município de Pelotas - RS. Do total de funcionários examinados, identificaram 13 $(10,24 \%)$ reagentes positivos com titulação de 1:25 a 1:100. As prevalências por abatedouros foram: A. $0,00 \%(0 / 22)$; B. 4,55\% (1/22); C. 8,33\% (1/12); D. $11,43 \%(4 / 35)$; E. $14,28 \%(2 / 14)$ e F. $22,73 \%(5 / 22)$, não havendo diferença estatística significativa entre os mesmos, embora a ausência de casos no abatedouro A. Em termos de tempo de serviço no abatedouro, encontraram uma prevalência de $11,43 \%$ (4/35) em indivíduos com menos de um ano de serviço, e uma prevalência de 11,39\% (9/79) em indivíduos com mais de um ano de serviço, sendo que $49,61 \%$ dos funcionários possuíam mais do que quatro anos de serviço. Em termos de tarefas executadas, quando compararam funcionários do abate ( $8 / 59$ com 13,56\%), triparia (4/15 com $26,67 \%$ ) e outros setores (administrativos e de limpeza 1/40 com 2,5\%), também não houve diferença estatisticamente significativa (CESARINI et al, 1996).

Almeida et al. (2000) realizando um estudo epidemiológico tipo casocontrole realizado em Uberlândia, Minas Gerais, Brasil, pesquisaram a ocorrência de brucelose em bovinos com bursite cervical, abatidos no período de agosto de 1993 a julho de 1994. O diagnóstico sorológico de brucelose foi realizado mediante a prova de soroaglutinação rápida em placa. Utilizaram-se 30 animais com o quadro e, como controle, 90 bovinos sem a patologia. Dos animais com bursite, $13,3 \%$ foram brucélicos, contra $5,6 \%$ do grupo controle. Dentre aqueles com brucelose e bursite, as bolsas continham fibrina (40\%) e projeções digitiformes (33,3\%). Apenas nas bursites dos sorologicamente negativos encontram-se presença de pus, de nódulos e de líquido viscoso. No âmbito da Saúde Pública e Ocupacional, sugere-se a atenção de técnicos e profissionais, visando diminuir o risco de infecção e evitar contaminação de carcaças, equipamentos e instalações.

Em 2001, Freitas et al. pesquisaram sobre o abate clandestino de suínos, uma prática condenável que ocorre no país e representa um dos mais graves fatores de risco, pela exposição coletiva a agentes infecciosos, como aqueles 
MEIRELLES-BARTOLI, R.B., SOUSA, D.B. e MATHIAS, L.A. Aspectos da brucelose na saúde pública veterinária. PUBVET, Londrina, V. 8, N. 10, Ed. 259, Art. 1722, Maio, 2014.

que são transmitidos ao homem pelo contato com animais, pela ingestão de alimentos de qualidade sanitária suspeita e pela contaminação do meio ambiente. Contudo, apesar das evidências, o abate clandestino tem sido negligenciado como fator de risco na ocorrência da brucelose zoonótica. Um total de 59 amostras de soros de suínos, procedentes de vários locais de abate clandestino, apresentaram ao "card test" e à soroaglutinação rápida anticorpos anti-Brucella e títulos de anticorpos sugestivos de infecção. Ações e medidas e vigilância sanitária são recomendadas para prevenir o risco potencial de infecção brucélica zoonótica.

Em julho de 2006 ocorreu um surto de brucelose suína em uma propriedade no município de Jaboticabal, Estado de São Paulo, associado a infecções humanas relatado por Meirelles-Bartoli et al. (2012). Na granja existiam aproximadamente 300 matrizes e 1.500 animais na terminação. Várias matrizes haviam abortado, outras apresentavam descarga vaginal, e três desenvolveram paralisia dos membros pélvicos. Das 271 matrizes testadas sorologicamente pelo teste de fixação de complemento, $254(93,7 \%)$ foram positivas. O biovar 1 de B.suis foi cultivado a partir de material de 14 fetos e de 6 matrizes necropsiadas na fazenda. Catorze trabalhadores da granja foram submetidos a provas sorológicas, e três deles apresentaram títulos de anticorpos contra brucelas lisas na prova de aglutinação. Uma mulher de 39 anos, que trabalhava na maternidade da granja e que tinha contato direto com os abortos fetais, apresentou um título de $480 \mathrm{UI} / \mathrm{mL}$ e sinais clínicos (febre intermitente, suores noturnos profusos, fraqueza, mal-estar); um homem, de 27 anos, apresentou título de $200 \mathrm{UI} / \mathrm{mL}$; e outro, de 25 anos, títulos de 60 $\mathrm{UI} / \mathrm{mL}$; ambos tinham contato direto com os fetos, mas não apresentaram sintomatologia. Os resultados encontrados por estes autores indicam que, apesar da redução da incidência de brucelose suína no Brasil, infecção por B.suis ainda ocorre, sendo um risco para a saúde humana e animal.

Apesar da importância da brucelose suína, não existe muita informação atualizada sobre a situação epidemiológica no Brasil. Por essa razão, MeirellesBartoli et al. (2013) pesquisaram a frequência de anticorpos contra Brucella 
MEIRELLES-BARTOLI, R.B., SOUSA, D.B. e MATHIAS, L.A. Aspectos da brucelose na saúde pública veterinária. PUBVET, Londrina, V. 8, N. 10, Ed. 259, Art. 1722, Maio, 2014.

em animais abatidos e avaliaram o risco de ocorrência de brucelose suína nos trabalhadores de um estabelecimento frigorífico no Estado de São Paulo. Durante o período de julho de 2008 a janeiro de 2010 foram colhidas 1.100 amostras de sangue suíno, machos e fêmeas adultos, e também de vinte e quatro funcionários que desenvolviam atividades no frigorífico, distribuídos nas seções da linha de abate (dessensibilização, sangria, esfola, oclusão de reto e retirada do casco, chamuscamento, evisceração, triparia, divisão da carcaça, e inspeção), armazenagem, embarque e transporte das carcaças. Os resultados obtidos no período de realização deste estudo permitiram concluir que não foram encontrados suínos reagentes contra amostras lisas de Brucella entre os animais abatidos no frigorífico estudado e não ficou caracterizado o risco de exposição dos trabalhadores à brucelose suína. Entretanto, enfatizam a importância deste tipo de estudo para a segurança da saúde dos trabalhadores e das pessoas que irão consumir a carne dos animais abatidos nestes estabelecimentos.

\section{Transmissão por aerossóis}

A transmissão por aerossóis se demonstrou por experimentos e pesquisas. Nos laboratórios, um risco especial é representado pelas centrifugações de suspensões brucelares em centrífugas não hermeticamente fechadas. Entre 1938 a 1939 ocorreu um surto epidêmico com 45 estudantes da Universidade Estadual de Michigan, Estados Unidos, os quais estudavam no segundo e terceiro andar de um edifício, em cujo sótão se alojava um laboratório de pesquisas em brucelose. $\mathrm{Na}$ investigação destes casos, mostrou-se que o único modo possível de transmissão foi por via aerógena (ACHA \& SZYFRES, 2001).

Durante 25 anos foi feito um levantamento com o pessoal exposto ou infectado com agentes patogênicos pelo Centro Nacional de Doenças Animais de Iowa, EUA. Um total de 128 funcionários de laboratório, associados à exposição de agentes de doenças infecciosas foi relatado. Destes expostos, 103 foram diagnosticados, pois conhecia-se o acontecimento da infecção acidental. Os outros 25 foram identificados somente após o desenvolvimento 
MEIRELLES-BARTOLI, R.B., SOUSA, D.B. e MATHIAS, L.A. Aspectos da brucelose na saúde pública veterinária. PUBVET, Londrina, V. 8, N. 10, Ed. 259, Art. 1722, Maio, 2014.

das manifestações clínicas ou sorológicas da infecção. Trinta e quatro casos de infecção adquiridos em laboratório foram revistas. Três classes de organismos foram encontrados, Chlamydia sp, Brucella spp e Mycobacterium sp, sendo que $76 \%$ das infecções encontradas, a Brucella spp foi a mais frequentemente isolada. A causa mais comumente relatada de exposição estava associada com o uso de seringas hipodérmicas. As vias de exposição desconhecidas supõem ocorrer por aerossóis (MILLER et al., 1987).

De maio a setembro de 1988, foram relatados oito casos de infecção por B.melitensis em trabalhadores de um laboratório de Microbiologia de um hospital em Michigan, EUA. As investigações revelaram que seis semanas antes de ocorrer o surto, uma Brucella isolada congelada de um paciente hospitalizado há três anos tinha sido descongelada e subcultivada sem o uso de um local de segurança biológica adequado. Este isolamento clínico foi subsequente a identificação da B.melitensis, biótipo 3, identificadas no isolamento dos trabalhadores. Assim se supõe que a transmissão ocorreu por via aerógena (STASZKIEWICZ et al., 1991).

Em 1997, sete casos de infecção por B.melitensis adquiridos em laboratório foram detectados entre o pessoal de um hospital de um centro médico que atende uma área endêmica no sudeste de Israel. Embora o início dos sintomas, em seis pacientes, ocorreu durante um período de duas semanas, sugerindo uma fonte de exposição, o biótipo analisado mostrou que o surto foi causado por três diferentes biotipos da B.melitensis, indicando exposições múltiplas. Revisões dos registros do laboratório mostraram que durante o ano de 1997, o microorganismo foi recuperado de 146 culturas de sangue e fluido sinovial, e que durante dois meses em que ocorreram os casos adquiridos em laboratório, 53 de 503 garrafas de cultura de sangue aeróbica positiva $(10,0 \%)$ cresceram B.melitensis. A investigação epidemiológica não revelou a fonte do surto, e não houve evidências no rompimento das práticas de segurança de laboratório que deveriam ser demonstradas (YAGUPSKY et al., 2000). 
MEIRELLES-BARTOLI, R.B., SOUSA, D.B. e MATHIAS, L.A. Aspectos da brucelose na saúde pública veterinária. PUBVET, Londrina, V. 8, N. 10, Ed. 259, Art. 1722, Maio, 2014.

Na Itália também foi relatado um surto de infecção de B.abortus adquirida em laboratório originado pelo rompimento acidental de tubos de centrifuga. Um total de doze trabalhadores de laboratório foi infectado, com um tempo de incubação ao redor de seis semanas a cinco meses. Títulos de anticorpos foram avaliados semanalmente em todo o pessoal exposto, permitindo o diagnóstico da infecção na maioria dos casos antes do início dos sintomas clínicos, assim o tratamento pôde ser administrado (FIORI et al., 2000).

\section{Transmissão Inter-humana}

A transmissão de humano para humano é raro (ACHA \& SZYFRES, 2001). Infecção neonatal já foi descrita e pode ser adquirida via transplacentária ou durante o parto, mas nunca havia sido descrito um caso como o que ocorreu no departamento de pediatria de um hospital em Istambul, na Turquia, onde uma mãe com brucelose, provavelmente transmitiu a infecção para seu filho de três meses através do leite materno (PALANDUZ et al, 2000).

Existem casos relatados de transmissão via transfusão sanguínea, mas um único caso de brucelose transmitida por transplante de medula óssea foi relatado também na Turquia em um menino de oito anos com diagnóstico de anemia de Fanconi. Em uma cultura rotineira de uma suspensão de medula houve o crescimento de B.abortus quatro dias após o transplante. Episódios febris ocorreram dois dias após o transplante e novamente após dezesseis dias. O primeiro episódio de febre respondeu bem com a antibioticoterapia, entretanto o segundo episódio não. A B.abortus foi isolada da cultura do sangue coletado durante o segundo episódio febril. A titulação de Brucella por aglutinação foi negativo. A antibioticoterapia com doxiciclina oral e gentamicina intravenosa foi um sucesso e não houve recidiva da infecção durante 13 meses. A cultura de sangue do doador foi positiva para B.abortus e anticorpos contra Brucella foram detectados em titulação de 1:320, trinta e dois dias após o transplante, quando o receptor apresentava febre e hepatoesplenomegalia. Assim enfatiza-se a necessidade de considerar a brucelose em pacientes transplantados, sugerindo que tanto o doador quanto $o$ 
MEIRELLES-BARTOLI, R.B., SOUSA, D.B. e MATHIAS, L.A. Aspectos da brucelose na saúde pública veterinária. PUBVET, Londrina, V. 8, N. 10, Ed. 259, Art. 1722, Maio, 2014.

receptor devem ser avaliados para brucelose, especialmente em países onde a incidência desta infecção é relativamente alta (ERTEM, et al., 2000).

A transmissão sexual também é possível. Mantur e colaboradores relataram a transmissão sexual de B.melitensis em um jovem casal indiano (MANTUR et al., 1933 citado por WYATT, 1996), assim como outros pesquisadores observaram a infecção por esta via de transmissão da B.melitensis, mas Thalhammer et al. (1998) publicaram um relato de um caso de infecção devido a B.abortus provavelmente adquirido via contato sexual em um jovem casal austríaco. Um homem de 25 anos deu entrada em um hospital por causa de febre (aproximadamente $39^{\circ} \mathrm{C}$ ), dores de cabeça, artralgia e redução de 6 kilos. Seus sintomas começaram três meses antes da hospitalização, quando ele retornou de uma viagem feita para a Síria onde ele consumiu queijo de leite de cabra fresco. O tratamento sintomático consistiu de paracetamol e ácido mefenamitico. Seis semanas depois o tratamento foi complementado com roxitromicina, $300 \mathrm{mg}$, mas os calafrios e o suor abundante continuaram. Na entrada ao hospital ele estava num quadro de sofrimento moderado. Uma cultura de sangue rotineira mostrou-se positiva pra B.abortus. O teste de soroaglutinação para antígenos de Brucella foi positivo. A terapia com doxiciclina, $400 \mathrm{mg}$ e rifampicina $600 \mathrm{mg}$ foi instituído. Em poucos dias as condições do paciente haviam melhorado. Ele já não apresentava um quadro de pirexia. Dois meses depois do início dos sintomas do paciente, sua namorada começou a desenvolver alguns sintomas: febre, suores abundante, artralgia e linfoadenopatia cervical. Cinco semanas depois do início dos sintomas, ela deu entrada no hospital, onde a cultura sanguínea deu positivo pra B.abortus. Ela foi medicada com rifampicina e co-trimoxazole porque sabia-se da hipersensibilidade da paciente à doxiciclina. Ela recuperou-se sem maiores complicações. Embora o jovem homem tivesse um histórico de viagem à Síria e recordou-se de ter consumido produtos lácteos sem pasteurização, sua namorada não foi ao Oriente Médio e negou ter ingerido algum queijo ou leite importado. Na Áustria, bem como no resto da Comunidade Européia, os bovinos, caprinos e ovinos estão livres de infecções por B.abortus. Produtos 
MEIRELLES-BARTOLI, R.B., SOUSA, D.B. e MATHIAS, L.A. Aspectos da brucelose na saúde pública veterinária. PUBVET, Londrina, V. 8, N. 10, Ed. 259, Art. 1722, Maio, 2014.

lácteos são produtos quase que exclusivamente feitos com leite pasteurizado e estão sujeitos a testes rotineiros de qualidade e microbiológicos. Sustenta-se por tanto que a transmissão tenha ocorrido via transmissão sexual, pois o casal admitiu ter relações sexuais sem proteção.

\section{A DOENÇA NOS SERES HUMANOS}

A brucelose nos seres humanos é uma enfermidade septicêmica, que começa de forma brusca, manifestando-se com febre contínua ou intermitente, com calafrios e suadores. Cursa com sintomatologia nervosa, como irritação, nervosismo e depressão. Os sintomas mais comuns nos seres humanos é a insônia, impotência sexual, constipação, anorexia e dores generalizadas (ACHA \& SZYFRES, 2001). Os seres humanos infectam-se por meio do contato direto com animais infectados ou indiretamente, através da ingestão de produtos de origem animal ou, mais raramente, por inalação de aerossóis. O grande risco para a saúde pública por B.abortus, decorre principalmente pela ingestão de leite cru ou de produtos lácteos não submetidos a tratamento térmico (queijo fresco, iogurte, creme, etc.), oriundos de animais infectados, mas também é caracterizada como uma enfermidade ocupacional. A carne crua com restos de tecido linfático e o sangue de animais infectados podem conter microorganismos viáveis, e portanto, de igual modo representam risco para a população humana consumidora (BRASIL, 2001). A brucelose suína tem um risco proporcionalmente maior que a brucelose bovina, pois apresenta um maior grau de patogenicidade para humanos. Existe um grande número de B.suis nos tecidos, proporcionando uma grande área de exposição para as pessoas que estão em contato com suínos. A infecção por B.suis em humanos é uma doença ocupacional, atingindo produtores, veterinários, trabalhadores de frigoríficos e outras profissões ligadas ao contato direto com animais ou com produtos de origem animal (DEYOE, 1992). 
MEIRELLES-BARTOLI, R.B., SOUSA, D.B. e MATHIAS, L.A. Aspectos da brucelose na saúde pública veterinária. PUBVET, Londrina, V. 8, N. 10, Ed. 259, Art. 1722, Maio, 2014.

\section{Complicações clínicas no homem}

O período de incubação da doença é, em média, de uma a três semanas, às vezes prolongando-se por muitos meses. A doença pode variar de suave a bastante severa, e os indivíduos impúberes parecem ser menos suscetíveis. Há redução na produtividade pela convalescença demorada e curso crônico. Os sinais mais evidentes da brucelose nos seres humanos são aqueles observados nos quadros de infecção generalizada aguda e ocorrem na fase de bacteremia: febre contínua e intermitente, respiração acelerada, calafrios e suores noturnos profusos, geralmente apresentando um odor particular (ACHA \& SZYFRES, 2001).

Astenia, fadiga, constipação, anorexia, cefaléia, artralgia e problemas de sistema nervoso levando a neurastenia, depressão, impotência sexual e insônia também são sintomas manifestados em casos agudos de brucelose. Há relatos de complicações mais sérias como meningoencefalites, neurites periféricas, artrites supurativas e endocardite vegetativa (ACHA \& SZYFRES, 2011). Gouider et al. (1999) descreveram oito casos de pacientes hospitalizados apresentando sinais neurológicos decorrente de infecção por brucela. A apresentação clínica foi de meningoencefalite em três casos, meningoencefalomielite em um, meningite com compressão da medula espinhal em outro, poliradiculoneurite aguda em dois casos e poliradiculoneurite crônica em um outro. Em sete pacientes, o nervo auditivo foi lesado. O líquor cerebral analisado revelou meningite linfocítica e uma alta concentração protéica em todos os casos. Foi feito o isolamente de B.melitensis por meio da cultura do sangue de uma paciente e do liquor de outros dois. O tratamento instituído teve sucesso em sete dos casos.

Com o agravamento do quadro surgem artrites, espondilites, brusites, dores reumáticas e neuralgia nas costas, inflamação na medula óssea e em muitos órgãos onde a bactéria consegue se alojar, principalmente fígado, baço e linfonodos (ACHA \& SZYFRES, 2001). A espongilite é uma das mais frequentes complicações osteoarticular por infecção por Brucella spp, mas com envolvimento da medula cervical é raro. O Departamento de Bacteriologia 
MEIRELLES-BARTOLI, R.B., SOUSA, D.B. e MATHIAS, L.A. Aspectos da brucelose na saúde pública veterinária. PUBVET, Londrina, V. 8, N. 10, Ed. 259, Art. 1722, Maio, 2014.

Clínica e Doenças Infecciosas, da Faculdade de Medicina, da Universidade de Istambul, na Turquia, relatou um caso de espongilite cervical com abscesso epidural anterior paravertebral causado por infecção por Brucella spp, que resultou em deficiência neurológica. O diagnóstico foi baseado no histórico clínico e sustentado pela sorologia positiva para brucelose, evidências de achados radiológicos e histológicos (BASARANOGLU et al., 1999).

A orquite provocada por Brucella spp é uma complicação rara ( 2 a14\%) e sua forma necrosante deve ser distinguida das provocadas por outros patógenos (Mycobacterium e Salmonella). Tratamento com antibióticos específicos ajuda a evitar uma orquiectomia desnecessária e prevenir doenças infecciosas no testículo contralateral, bem como infecções sistêmicas. Foi relatado um caso de epididimite-orquite por Brucella com um aumento escrotal agudo em um homem de 19 anos residente na cidade de Valência, Espanha. A anamnese foi crucial no diagnóstico da rara infecção testicular (ALAPONT, 2004). Outros 26 casos de epididimite-orquite por Brucella em adultos foram descritos na Arábia Saudita entre os anos de 1983 a 2000 por Memish \& Venkatesh (2001).

No ano de 1999 foi publicado pelo Departamento de Bacteriologia Clínica e Doenças Infecciosas, da Faculdade de Medicina, da Universidade de Ankara, no Hospital Ibni Sina, na Turquia, um caso de uma mulher gestante com um abscesso bilateral mamário devido a infecção por B.melitensis (COKCA et al, 1999).

O diagnóstico clínico da brucelose humana é difícil, pois os sintomas são inespecíficos. Há necessidade, portanto, de uma boa anamnese e de exames laboratoriais complementares diretos e indiretos (PAULIN \& FERREIRA, 2003).

\section{SITUAÇÃo NACIONAL DA BRUCELOSE E SEU CONTROLE}

Nos seres humanos, o enfoque mais racional para prevenção da brucelose consiste no controle e na eliminação da infecção dos reservatórios animais, tal como se há demonstrado em vários países europeus e americanos. Parte da 
MEIRELLES-BARTOLI, R.B., SOUSA, D.B. e MATHIAS, L.A. Aspectos da brucelose na saúde pública veterinária. PUBVET, Londrina, V. 8, N. 10, Ed. 259, Art. 1722, Maio, 2014.

população pode ser protegida mediante a obrigação da pasteurização do leite. A prevenção da infecção em grupos ocupacionais é mais difícil, e deve basearse na educação sanitária, o uso de proteção individual adequada, como roupas e luvas, e a supervisão médica (ACHA \& SZYFRES, 2001).

A brucelose foi detectada pela primeira vez no Brasil em 1913, por Gonçalves Carneiro, que relatou um caso de brucelose humana. Desde então, várias pesquisas epidemiológicas têm revelado a presença desta enfermidade em rebanhos no país (POESTER et al, 2002).

Em 1936, Desidério Finamor detectou pela primeira vez, a brucelose em bovinos no Rio Grande do Sul, por sorodiagnóstico (PAULIN \& FERREIRA, 2003). As primeiras tentativas de controle da brucelose bovina no país datam dos anos de 1940 a 1950. As medidas propostas eram restritas a exames sorológicos de tecidos de bezerros abortados com segregação de regentes e vacinação com a estirpe vacinal B19 (POESTER et al, 2002).

Depois de alguns anos e muito pouco progresso, uma nova linha de direção foi proposta com vistas a reforçar as medidas de controle. Isto incluía vacinação de todas novilhas com B19 e ativação de Comitês de Brucelose que incluíam representantes do governo da saúde pública e animal, fazendeiros e produtores de carne e leite (OIE, 1987).

Em 1954, Mário D'Apice propôs quatro planos de combate para a brucelose bovina baseados no programa americano: Plano A - sorodiagnóstico, sacrifício dos animais reagentes e repetição do teste em 30 dias dos não reagentes; Plano B - vacinação de bezerras e separação do rebanho em animais reagentes e não reagentes, sem sacrifício dos reagentes; Plano C vacinação de bezerras com idade entre 6 e 8 meses; e Plano D - vacinação de adultos, se necessária (PAULIN \& FERREIRA, 2003).

A partir de 1958, os animais importados para reprodução deveriam vir acompanhados de certificados negativos ao sorodiagnóstico. As provas deveriam ser repetidas na fronteira, e os animais reagentes sacrificados sem compensação ao proprietário. Outro regulamento foi o de Trânsito Interno de Animais, que permitia o movimento dos positivos somente para o matadouro, 
MEIRELLES-BARTOLI, R.B., SOUSA, D.B. e MATHIAS, L.A. Aspectos da brucelose na saúde pública veterinária. PUBVET, Londrina, V. 8, N. 10, Ed. 259, Art. 1722, Maio, 2014.

e os animais que fossem se apresentar em exposições deveriam ser livres da enfermidade (OIE, 1987).

Em 1975, um levantamento nacional mostrou a seguinte prevalência de brucelose em animais de cada região: norte $(4,1 \%)$; nordeste $(2,5 \%)$; centrooeste $(6,8 \%)$; sudeste $(7,5 \%)$ e sul $(4,0 \%)$ (BRASIL, 2001$)$.

Em 1976, outro decreto do Ministério da Agricultura propôs um Programa Nacional baseado principalmente na vacinação voluntária de bezerras, diagnóstico no rebanho, e testes e abate voluntário dos animais reagentes. $\mathrm{O}$ programa nunca foi completamente implantado, e a situação epidemiológica ficou estável, com alta prevalência da doença nos mais importantes rebanhos do país (PAULIN \& FERREIRA, 2003).

Em 1965, o estado do Rio Grande do Sul começou um programa de vacinação progressiva com $80 \%$ de cobertura de novilhas, e resultou em uma significante diminuição na prevalência da brucelose (POESTER et al, 2002).

Estudos estaduais da prevalência da brucelose bovina foram conduzidos durante estes anos. Em 1980, em Minas Gerais, a prevalência foi de 6,7\%. No Rio Grande do Sul, em 1986 estimou-se em 0,3\%. Em 1989, no Paraná foi de 4,6\%. Em Santa Catarina, em 1996, girava em torno de 0,6\% e em 1998, no Mato Grosso do Sul foi de $6,3 \%$ a frequência de animais soropositivos (BRASIL, 2001).

Em 2000, o Ministério da Agricultura começou a pesquisar a legislação e estratégias de controle de brucelose. O Programa Nacional de Controle e Erradicação da Brucelose e Tuberculose Animal (PNCEBT) foi instituído em 2001 pelo Ministério da Agricultura, Pecuária e Abastecimento (MAPA) com o objetivo de diminuir o impacto negativo dessas zoonoses na saúde humana e animal, além de promover a competitividade da pecuária nacional. Assim sendo, os métodos de controle da brucelose são bastante simples. O mais importante é conhecer muito bem tanto a epidemiologia da doença, quanto a população em que as ações deverão ser desenvolvidas, e escolher a melhor estratégia para implementá-las (BRASIL, 2006). A estratégia proposta através do PNCEBT pôde ser resumida em: 
MEIRELLES-BARTOLI, R.B., SOUSA, D.B. e MATHIAS, L.A. Aspectos da brucelose na saúde pública veterinária. PUBVET, Londrina, V. 8, N. 10, Ed. 259, Art. 1722, Maio, 2014.

- Credenciamento e capacitação de médicos veterinários, para a execução de atividades de diagnóstico e vacinação, através de cursos de treinamento;

- Vacinação obrigatória de bezerras bovinas e bubalinas de 3 a 8 meses de idade, com uma única dose de vacina da amostra 19 da B. abortus (B19), por médico veterinário cadastrado;

- Marcação obrigatória de todas as fêmeas vacinadas, no lado esquerdo da cara, com um "V", acompanhado do algarismo final do ano de vacinação;

- Certificação voluntária de propriedades livres: testes em todo rebanho, em um período mínimo de 9 meses, obtendo três resultados negativos consecutivos. Depois de certificada ficam obrigadas a repetir os testes anualmente nas fêmeas de idade igual ou superior a 24 meses, desde que vacinadas entre 3 e 8 meses;

- Certificação voluntária de propriedades monitoradas: testes anuais por amostragens, quando identificado um reagente positivo, todas as fêmeas com mais de 24 meses e os machos reprodutivos serão testados;

- Credenciamento de laboratórios para garantir capacidade de diagnóstico adequada, onde Médicos Veterinários credenciados realizam a prova do antígeno acidificado tamponado (AAT) como teste de triagem. Os animais com resultado positivo nesse teste podem ser classificados como infectados ou então podem ser submetidos a um teste confirmatório por um laboratório oficial, situação para a qual existem duas opções: a combinação das provas de soroaglutinação lenta e do 2-mercaptoetanol ( $S A L+2-M e$ ) ou então a reação de fixação de complemento (RFC). Para monitoramento da condição sanitária de propriedades certificadas de gado de leite seria utilizada prova do anel do leite;

- Marcação obrigatória de todos os animais positivos a teste de diagnóstico, no lado direito da cara com um "P" contido num círculo de oito centímetros de diâmetro;

- Abate obrigatório de animais positivos, em matadouros aprovados, no prazo máximo de trinta dias, após o diagnóstico e isolamento; 
MEIRELLES-BARTOLI, R.B., SOUSA, D.B. e MATHIAS, L.A. Aspectos da brucelose na saúde pública veterinária. PUBVET, Londrina, V. 8, N. 10, Ed. 259, Art. 1722, Maio, 2014.

- Controle de trânsito de reprodutores: para fins de trânsito interestadual de machos e fêmeas, destinados a reprodução, é obrigatória a apresentação de resultados negativos aos testes de diagnóstico, à qual a emissão de GTA fica condicionada. Os atestados de exames negativos serão válidos por 60 dias, a contar da data da colheita da amostra de sangue para o diagnóstico;

- Normas sanitárias para participação em exposições, feiras, leilões e outras aglomerações de animais: a emissão de GTA fica condicionada a atestados com resultados negativos a testes de diagnósticos, efetuados até 60 dias antes do início do evento, para animais acima de oito meses de idade (BRASIL, 2006).

\section{COMENTÁRIOS FINAIS}

Esta enfermidade deve ser tratada com medidas profiláticas eficientes visando a erradicação e prevenção como zoonose. Pode-se dividir estas medidas nos seguintes grupos:

- Medidas Médico Veterinárias: notificação dos casos de brucelose nos rebanhos às Autoridades Veterinária e Sanitárias competentes, seguindo as normas do PNCEBT, e campanhas de educação sanitária para a população.

- Medidas Gerais: obrigatoriedade da pasteurização e fervura do leite; evitar ingerir produtos lácteos crus, e evitar consumo de carnes e derivados sem estar devidamente cozidos.

- Medidas Individuais: uso de roupas especiais que evite o contato com o sangue, tecidos e secreções de animais por meio de luvas longas para proteção de braço e antebraço, botas longas e aventais impermeáveis.

Desta forma, a instituição de um trabalho conjunto multi-profissional, envolvendo setores da medicina humana e veterinária, associadas a órgãos oficiais de saúde pública e sanidade animal, visando à educação da população de uma forma em geral, deve ser considerada como forma de prevenção, controle e erradicação da brucelose. 


\section{REFERÊNCIAS}

ACHA, P.N.; SZYFRES, B. Brucelose. In: Zoonosis y enfermidades transmisibles comunes al hombre y a los animales. Washington Organización Panamericana de la Salud, Publicación Científica 503, 2001. p.14-37.

ALAPONT, M.J.A; GÓMEZ, L.L.; DELGADO, F.; PALMERO, L.J.M.; PACHECO, J.J.B; PONTONES, L.J.M.; JIMÉNEZ, F.J.C, Orquiepididimitis por Brucella. Actas Urol. Esp., v.28, n.10, p.774-6, 2004.

ALMEIDA, L.P.; REIS, D.O.; GERMANO, P.M.L., Brucelose em bovinos com bursite cervical diagnosticada em abatedouro sob inspeção federal. Ciência Rural, v.30, n.2, p.287-91, 2000.

ALTON, G.G.; GULASEKHARAM, J., Brucellosis as a human health hazard in Austrália. Australian Veterinary Journal, v.50, p.209- 15, 1974.

ALTON, G.G. Brucella suis. In: NIELSEN, K.; DUNCAN J.R. Animal Brucellosis. Boca Raton, CRC Press, p.411-422, 1990.

BARUFFA, G., Prevalência sorológica da brucelose na zona sul do Rio Grande do Sul (Brasil). Rev. Inst. Med. Trop., v.20, n.2, p.71-5, 1978.

BASARANOGLU, M.; MERT, A.; TABAK, F.; KANBEROGLU, K.; AKTUGLU, Y., A case of cervical Brucella spondylitis with paravertebral abcess and neurological deficits. Scand. J. Infect. Dis., v.31, n.2, p.214-5, 1999.

BATHKE, W. Brucelose. In: BEER, J. Doenças Infecciosas em Animais Domésticos. São Paulo: Roca, 1999. p.163-78.

BOTELHO, A.P.; GALINDO, G.A.R.; SILVA, L.B.G.; COELHO, R.M.S.; LIMA, E.T., Recuperação de Brucella abortus do leite in natura procedente de vacas soropositivas dos municípios de pedra e Venturosa - PE: aspectos de saúde pública. Higiene Alimentar, v.14, n.73, p.72-7, 2000.

BRASIL, Ministério da Agricultura e do Abastecimento. Departamento de Defesa Animal. Instrução Normativa no 2, de 10 de janeiro de 2001. Institui o Programa Nacional de Controle e Erradicação da Brucelose e Tuberculose (PNCEBT). Republicada no Diário Oficial da República Federativa do Brasil, Poder Executivo, 16 jan. 2001. Secção 1, p. 11-17.

BRASIL, Ministério da Agricultura, Pecuária e Abastecimento. Secretaria de Defesa Agropecuária - Departamento de Saúde Animal, 2006. Programa Nacional de Controle e Erradicação da Brucelose e Tuberculose (PNCEBT) - Manual Técnico. Brasília: MAPA / DAS / DSA, 2006, 188p.

BREW, S.D.; PERRETT, L.L.; STACK, J.A.; MACMILLAN, A.P.; STAUNTON, N. J. Human exposure to Brucella recovered from a sea mammal. Veterinary Record, v.144, p.483, 1999.

CAPASSO, L. Bacteria in two-millennia-old cheese, and related epizoonoses in Roman populations. Journal of Infection, v.45, p.122-127, 2002.

CESARINI, C.C.; PEREIRA, H.C.P.; SOARES,C.L.; MEDINA, R.B.; BROD, C.S., Anticorpo antiBrucella abortus, em magarefes no município de Pelotas, RS. In: Anais do XXIV Congresso Brasileiro de Medicina Veterinária, 1996, Resumos, 1996. p.138-9. 
COELHO, L.M.; MARTINS, L.; EVANGELISTA, F.H., Prevalência da Brucelose nos trabalhadores de matadouro em São Luis, Estado do Maranhão. Revista Brasileira de Medicina Veterinária, v.17, n.2, p.85-8, 1995.

COKCA, F.; AZAP, A.; MECO, O., Bilateral mammary abcess due to Brucella melitennsis. Scand. J. Infect. Dis., v.31, n.3, p. 318-9, 1999.

CORBEL, M.J. Brucellosis: an overview. Emerging Infectious Diseases, v.3, n.2, p.213-221, 1997.

CORRÊA, W.M.; CORRÊA, C.N.M. Brucelose. In:Enfermidades Infecciosas dos Mamíferos Domésticos. 2a Ed. Rio de Janeiro: Medsi, 1992. 843p. Cap.20. p.195-218.

DE, B.K.; STAUFFER, L.; KOYLASS, M.S.; SHARP, S.E.; GEE, J.E.; HELSEL, L.O.; STEIGERWALT, A.G.; VEGA, R.; CLARK, T.A.; DANESHVAR, M.I.; WILKINS, P.P.; WHATMORE, A.M. Novel Brucella Strain (BO1) associated with a prosthetic breast implant infection. Journal of Clinical Microbiology, v.46, n.1, p.43-49, 2008.

DEYOE, B.L. Brucellosis. In: LEMAN, A.D.; STRAW, B.E.; MENGELING, W.L.; D'ALLAIRE, S.; TAYLOR, D.J. Diseases of swine. 8 th ed. Ames: Iowa State University Press, 1992. Cap. 52, p. 599-606.

EAGLESOME, M.D.; GARCIA, M.M. Disease risks to animal health from artificial insemination with bovine semen. Revue Scientifique et Technique de L'Office Intrenational des Epizzoties, v. 16, n. 1, p. 215-225, 1997.

ERTEM, M.; KUREKCI, A.E.; AYSEV, D.; UNAL, E.; IKINCIOGULLARI, A., Brucellosis transmitted by bone marrow transplantation. Bone Marrow Transplnt, v.26, n.2, p.225-6, 2000.

FACHARZT, A.R.A.M.; HARLAND, P.S.E.G. Brucelosis in children. Annals of Saudi Medicine, V.6, n.4, 1986.

FEITOSA, M. H.; BITTAR, C. R.; GOMES, S. P., Brucelose: levantamento sorológico no estado de São Paulo no período de 1977 a 1987. Veterinária \& Zootecnia, v.3, p.9-15, 1991.

FIORI, P.L.; MASTRANDREA, S.; RAPPELLI, P.; CAPPUCCINELLI, P., Brucella abortus infection acquired in microbiology laboratories. J. Clin. Microbiol., v.38, n.5, p.2005-6, 2000.

FOSTER, G.; OSTERMAN, B.S.; GODFROID, J. ; JACQUES,I.; CLOECKAERT, A. Brucella ceti sp. nov. and Brucella pinnipedialis sp. nov. for Brucella strains with cetaceans and seals as their preferred hosts. International Journal of Systematic and Evolutionary Microbiology, v.57, p.2688-2693, 2007.

FREITAS, J. A.; GALINDO, G. A. R.; SANTOS, E. J. C.; SARRAF, K. A.; OLIVEIRA, J. P.; Risco de brucelose zoonótica associado a suínos de abate clandestino. Revista Saúde Pública, v.35, n.1, 2001.

GARCÍA-CARRILLO, C.; TUROVETZKY, A.; LUCERO, N., Especies y biotipos de Brucella aislados del hombre en la Argentina: comprobación de la infección humana por $B$. abortus biotipo 4. Medicina, v.45, n.1, p.20-1, 1985.

GOUIDER, R.; SAMET, S.; TRIKI, C.; FREDJ.; GARGOURI, A.; BAHRI, F.; BEN GHORBEL, I.; KASRAOUI, A.; MHIRI, C.; MRABET, A., Neurological manifestations indicative of brucellosis. Rev. Neurol., v.155, n.3, p.215-8, 1999. 
INTERNATIONAL COMMITTEE ON BACTERIAL TAXONOMY. SUBCOMMITTEE ON TAXONOMY OF BRUCELLA, 2010. Disponível em: <http://www.the-csp.org/ subcoms/Brucella.htm>. Acesso em: 10 abril de 2010.

LANGONI, H.; ICHIHARA, S. M., SILVA, A . V., et al. Isolation of brucella spp from milk of brucellosis positive cows in São Paulo and Minas Gerais states. Brazilian Journal Veterinary Residence Animals Sciencs, v.37, n.6, p.444-8, 2000.

LUSHSINGER, D.W.; ANDERSON, R.K., WERRING, D.F. A swine brucellosis epizootic. Journal of the American Veterinary Medical Association, n.147, p.632-636, 1965.

MARQUES, J.; CLEMENTE, J. L.; FERREIRA, P.; FERREIRA, M.; SILVA, I., Brucelose, um problema de Saúde Pública. Revista Saúde Infantil, v.27, n.22/1, p.27-32, 2000.

McDONALD, W.L., JAMALUDIN, R., MacKERETH, G.; HANSEN, M.; HUMPHREY, S.; SHORT, P.; TAYLOR, T.; SWINGLER, J.; DAWSON, C. E.; WHATMORE, A. M.; STUBBERFIELD, E.; PERRETT, L. L.; SIMMONS, G. Characterization of a Brucella sp. strain as a marine-mammal type despite isolation from a patient with spinal osteomyelitis in New Zealand. Journal of Clinical Microbiology, v.44, n.12, p.4363-4370, 2006.

MEIRELLES-BARTOLI, R.B., MATHIAS, L.A. AND SAMARTINO, L.E., Brucellosis due to Brucella suis in a swine herd associated with a human clinical case in the State of São Paulo, Brazil. Tropical Animal Health and Production, 44, p.1575-1579, 2012.

MEIRELLES-BARTOLI， R.B.; SOUSA, D.B.; CRUZ, C.A., MORAES, F.C.; ASSIS, N.A. ; MATHIAS, L.A. Levantamento sorológico de brucelose em suínos e magarefes de um frigorífico da região noroeste do Estado de São Paulo, Brasil. Revista Higiene Alimentar, v. 27, n. 218/219, p. , 2013.

MEMISH, Z.A.; VENKATESH, S., Brucellar epididymo-orchitis in Saudi Arabia: a retrospective study of 26 cases and review of the literature. BJU Int, v.88, n.1, p.72-6, 2001.

MÉNDEZ, M.C.; PÁEZ, J.A.; CORTÉS-BLANCO,M.; SALMORAL, C.E.; MOHEDANO,E.; PLATA,C.; VARO, B.A.; MARTÍINEZ, N.F., Brucellosis outbreak due to unpasteurized raw goat cheese in Andalucia (Spain), January - March 2002. Euro Surveill, v.8, n.7, p.164-8, 2003.

MILLER, C.D.; SONGER, J.R.; SULLIVAN, J.F., A twenty-five year review os laboratory-acquired human infections at the national Animal Disease Center. Am. Ind. Hyg. Assoc. J., v.48, n.3, p.271-5, 1987.

MISHAL, J.; BEM-ISRAEL, N.; LEVIN, Y.; SHERF, S.; JAFARI, J.; EMBON, E.; SHERER, Y. Brucellosis outbreak: analysis of risk factors and serologic screening. Int. J. Mol. Med., v.4, n.6, p.655-8, 1999.

NICOLETTI, P. An evaluation of serologic tests used to diagnose brucellosis in buffaloes (Bubalus bubalis). Tropical Animal Health Prodution, v.24, n.1, p.40-44, 1992.

OIE - Organização Internacional de Epizoótia. Brucelosis bovina, ovina y caprina. Série Técnica n.6, 282p, 1987.

PALANDUZ, A.; PALANDUZ, S.; GULER, K.; GULER, N., Brucellosis in a mother and her young infant: probable transmission by breast milk. Int. J. Infect. Dis., v.4, n.1, p.55-6, 2000.

PAULIN, L. M.; FERREIRA, J. S., Combate à Brucelose Bovina. Situação Brasileira. Jaboticabal: FUNEP, 2003. 154 p. 
POESTER, F.P.; GONÇALVES, V.S.P.; LAGE, A.P., Brucellosis in Brazil. Veterinary Microbiology, v.90, p.55-62, 2002.

SCHLABRITZ-LOUTSEVITCH， N.E.; WHATMORE， A.M.; QUANCE， C.R.; KOYLASS, M.S.; CUMMINS, L.B.; DICK J.R.; SNIDER, C.L.; CAPPELLI, D.; EBERSOLE, J.L.; NATHANIELSZ, P.W.; HUBBARD, G.B. A novel Brucella isolate in association with two cases of stillbirth in nonhuman primates - first report. Journal of Medical Primatology, v.38, p.70-73, 2009.

SCHOLZ, H.C.; HUBALEK, Z.; SEDLÁCEK, I.; VERGNAUD, G.; TOMASO, H.; DAHOUK, S.A.; MELZER, F.; KÄMPFER, P.; NEUBAUER, H.; CLOECKAERT, A.; MAQUART, M.; ZYGMONT, M.S.; WHATMORE, A.M.; FALSEN, E.; BAHN, P.; GÖLLNER, C.; PFEFFER, M.; HUBER, B.; BUSS, H.J.; NÖCKLER, K. Brucella microti sp. nov. isolated from the common vole Microtus arvalis. International Journal of Systematic and Evolutionary Microbiology, v.58, p.375-382, 2008.

SCHOLZ, H.C.; NÖCKLER, K.; GÖLLNER, C.; BAHN, P.; VERGNAUD, G.; TOMASO, H.; AL DAHOUK, S.; KÄMPFER, P.; CLOECKAERT, A.; MAQUART, M.; ZYGMUNT, M.S.; WHATMORE, A.M.; PFEFFER, M.; HUBER, B.; BUSSE, H.J.; DE, B.K. Brucella inopinata sp. nov. isolated from a brest implant infection. International Journal of Systematic and Evolutionary Microbiology. v.60, p. 801-808, 2010.

SOBESTIANSKY, J., DALLA COSTA, O.A., PERUZZO, B.F. Sistema de produção ao ar livre: estudo da prevalência de infecções urinárias em fêmeas em produção. In: CONGRESO NACIONAL DE PRODUCCIÓN PORCINA, 3; JORNADAS DE ACTUALIZACIÓN PORCINA, 8, 1994, Rosario, Argentina. Anais... Rosario: Universidad Nacional de Rosario, v.1, p. S-21, 1994.

SOHN, A.H.; PROBERT, W.S.; GLASER, C.A.; GUPTA, BOLLEN, A.W.; WONG, J.D.; GRACE, E.M.; N.; MCDONALD, W.C. Human neurobrucellosis with intracerebral granuloma caused by a marine mammal Brucella spp. Emerging Infectious Diseases, v.9, p.485- 488, 2003.

SOUZA, A. P.; MOREIRA, D. C.; FÁVERO, M., Investigação da brucelose em bovinos e em consumidores humanos do leite. Revista Saúde Pública, São Paulo, n.11, p.238-47, 1977.

SPÍNOLA, A.G.; COSTA, M.D.M., Brucelose humana em operários de um frigorífico no município de Salvador - Bahia - Brasil, B. IBB Salvador, v.11, n.1, p.7-18, 1972.

STASZKIEWICZ, J.; LEWIS, C.M.; COLVILLE,J. ZERVOS, M.; BAND, J., Outbreak of Brucella melitensis among microbiology laboratory workers in a community hospital. Journal of Clinical Microbiology, v.29, n.2, p.287-90, 1991.

THALHAMMER, F.; EBERL, G.; KOPETZKI-KOGLER, U., Unsual route of transmission for Brucella abortus. Clinical Infectious Diseases, v.26, n.3, p.763-4, 1998.

TROY, S.B.; RICKMAN, L.S.; DAVID, C.E., Brucellosis in San Diego: epidemiology and species related differences in acute clinical presentations. Medicine, v.84, n.3, p.174-87, 2005.

WYATT, H. V., Brucella melitensis can be transmitted sexually. The Lancet, v.348, n.9027, p. $615,1996$.

YAGUPSKY, P.; PELED, N.; RIESENBERG, K.; BANAI, M., Exposure of hospital personnel to Brucella melitensis and occurrence of laboratory-acquired disease in an endemic area. Scand. J. Infect. Dis., v. 32, n.1, p.31-5, 2000. 